\title{
Weaning of Mechanically Ventilated Patients with COVID-19: Value of Modified Burns Wean Assessment Program Scores
}

\author{
Sherif Mohamed ${ }^{1 *}$, Sayed Abd Elshafy ${ }^{2}$, Nermeen Abdelaleem ${ }^{1}$ and Azza AbdElHaffez ${ }^{3}$ \\ ${ }^{1}$ Department of Chest Diseases and tuberculosis, Assiut University, Egypt \\ ${ }^{2}$ Department of Anaethesia and Intensive Care, Assiut University, Egypt \\ ${ }^{3}$ Department of Medical Physiology, Assiut University, Egypt
}

Submission: November 11, 2020; Published: December 01, 2020

*Corresponding author: Sherif A Mohamed, Associate Professor of Pulmonary Medicine, Department of Chest Diseases and Tuberculosis, Faculty of Medicine, Assiut University, 71516 Assiut, Egypt

\section{Abstract}

Background: Most patients with acute respiratory distress syndrome (ARDS) due to COVID-19 warrant intubation and mechanical ventilation (MV).

Methods: As COVID-19 is a relatively new disease to us, with distinct clinical and pathophysiologic features and with massive burden on the health care facilities, particularly the intensive care units (ICUs), it is wise to think in using tools that are feasible, easy and save time and money. Previous studies showed that modified Burns wean assessment program (mBWAP) is a good predictor of weaning success.

Results: mBWAP proved useful as a good predictor of successful weaning and extubation in patients requiring long-term MV longer than 21 days, as well as in patients with respiratory disorders admitted to the respiratory ICU.

Conclusion: Previous data for mBWAP are encouraging and deserve utilizing it as a predictor tool for weaning from MV in patients with COVID-19. Further prospective studies are warranted.

Keywords: COVID-19; Mechanical ventilation; Weaning; ARDS; Modified Burns wean assessment program

\section{Weaning Predictors of Mechanically Ventilated Patients}

Weaning predictors are those physiological tests used to predict whether a patient is likely to tolerate weaning [1,2]. Weaning predictors can be categorized as measurements of oxygenation and gas exchange, measurements of respiratory system load, measurements of respiratory muscle capacity, and integrative indices. Within these categories, some measurements may be further characterized as simple to measure at the bedside versus complex measurements that may require special equipment. Weaning predictor measurements should identify all patients ready to breathe independently and they should be safe and easy to perform, highly reproducible, and not subject to confounding influences. They should also use equipment and techniques that are routinely available in intensive care units (ICUs).
Even though many weaning parameters and predictors have been reported in the literature, there is no consensus on the most useful predictive indicators [3], particularly in patients with respiratory disorders [4]. Moreover, despite that rapid shallow breathing index (RSBI) was the most frequently used parameter, there is no evidence that RSBI-dependent weaning improves clinical outcomes, such as duration of weaning, duration of mechanical ventilation (MV), length of stay, or reintubation rate [5].

\section{Modified Burns Wean Assessment Program Scores}

The original checklist of Burns wean assessment program (BWAP) was developed as tool to measure patient's readiness for weaning from the ventilator. This tool evaluates parameters of patients' weaning from the ventilator systematically and examines 
all parameters related to pulmonary function, gas changes, physiological and psychological conditions of patients [6]. It is an easy-to-use checklist, and its parameters could be measured within 10 minutes. The modified version of BWAP was developed by Jiang, et al. [7] who proved that this tool was a good predictor of successful weaning and extubation in patients requiring LTMV for longer than 21 days. Their results also suggested that a m-BWAP score $\geq 60$ is associated with successful extubation outcomes. Jeong \& coworkers [4] prospectively enrolled 103 patients in a medical ICU and concluded that m-BWAP score was a good predictor of weaning success in patients with an endotracheal tube in place at first spontaneous breathing trial (SBT).

Recently, the utility of m-BWAP in predicting the weaning success in patients with respiratory disorders admitted to the respiratory ICU was studied in Egypt [8]. Patients with respiratory failure requiring MV for longer than 48hours were included. They were divided into successful and unsuccessful weaning groups according to their outcomes. A total of 91 patients were enrolled. The majority had chronic obstructive pulmonary diseases (COPD); $40 \%$, overlap syndrome (24\%), and obesity hypoventilation syndrome (OHS); 15\%. The successful group had significantly higher m-BWAP scores than that in the unsuccessful group (median 65; range 35 to 80 vs. median 45; range 30 to 65; $\mathrm{p}=0.000$ ), with area under the curve (AUC) of $0.854 ; 95 \%$ CI 0.766 to 0.919 ), $p$ value $<0.001$. At cut-off value of $\geq 55$, the sensitivity and specificity of m-BWAP to predict successful weaning were $73.77 \%$ and $84.85 \%$, respectively. The AUC for m-BWAP was significantly higher than that for RSBI [8].

\section{Modified burns wean assessment program scores and weaning of mechanically ventilated patients with COVID-19}

Although SARS-CoV and SARS-CoV-2 (COVID-19) have certain similarities in biological, epidemiological, and pathological characteristics, there is a unique important difference. During the SARS epidemic, a total of 8422 patients worldwide were infected with SARS-CoV, of whom 919 died, with a mortality rate of 9.5\%. However currently, more than 2.3 million people worldwide are infected with COVID-19, and a global case fatality rate of 4.9\% [9].

The major morbidity and mortality from COVID-19 is largely due to acute viral pneumonitis that evolves to acute respiratory distress syndrome (ARDS). Most patients with acute respiratory distress syndrome (ARDS) due to COVID-19 will warrant intubation and mechanical ventilation. Previous studies showed that mBWAP is a good predictor of weaning success $[4,7]$. As COVID-19 is a relatively new disease to us, with distinct clinical and pathophysiologic features and with massive burden on the health care facilities, particularly the intensive care units, it is wise to think in using tools that are feasible, easy and save time and money. We think that mBWAP will be an ideal one. However, before we expect this ideality, we should think in 2 important points. The first is Will implementing mBWAP in patients with COVID-19 be different from that in patients with chronic respiratory disorders [8]? In another way, patients with COVID-19 include those with previous chronic respiratory disorders as well as "de novo" patients, ie COVID-19 in previously health subjects.

Those 2 "phenotypes" of patients will be different in their lung compliance and mechanics, interaction with the ventilator, as well their duration of mechanical ventilation, and lastly their weaning. COVID-19 leads to an atypical form of acute respiratory distress syndrome with relatively well-preserved lung compliance despite severe hypoxemia. Extubation is a high-risk procedure in patients with COVID-19 because of direct contact with patients and exposure to airway droplets and aerosols. Therefore, it is of crucial importance to ensure that the decision to extubate is appropriate so that the patients are not harmed by extubation, and the hazards related to the cycle of reintubation and extubation are avoided [10]. An important goal of extubation is to ensure that patients tolerate extubation and to minimize the chance that they will require reintubation. High-risk factors for reintubation include age, Acute Physiology and Chronic Health Evaluation (APACHE) II score, RSBI, and positive fluid balance. A low $\mathrm{PaO}_{2} /$ $\mathrm{FiO}_{2}$ ratio at extubation may be a risk factor for reintubation due to respiratory insufficiency $[10,11]$. The second is, do we have enough comparative data for mBWAP to other weaning parameters? Are these data enough to expect utility of mBWAP in patients with COVID-19?

Data regarding the weaning process had shown an evolution from using single parameters in the respiratory system to a more global perspective which combines systemic parameters and overall patient status to predict the success of weaning and extubation. In a recent systemic review, 56 parameters or scores that can predict weaning or extubation outcomes were assessed. RSBI was the most studied and relied upon parameter for weaning and extubation success. Moreover, parameters beyond respiratory ones can predict weaning and extubation outcome [3]. Nevertheless, further clinical studies utilizing these comprehensive and global parameters need further evaluation prior to being relied up in clinical settings. To the best of our knowledge, mBWAP has not been tried in patients with COVID-19 yet. We wonder if prospective studies can be carried out on using mBWAP in patients with COVID-19.

\section{Conclusion}

Previous data for mBWAP are encouraging and deserve utilizing it as a predictor tool for weaning from MV in patients with COVID-19. Further prospective studies are warranted.

\section{References}

1. Epstein SK (2003) Weaning from ventilatory support. In: Textbook of Pulmonary Diseases, ( $7^{\text {th }}$ edn.), Crapo JD, Glassroth J, Karlinsky J, King TE (Eds), Lippincott, Williams \& Wilkins, Philadelphia, USA, pp 1089.

2. Meade M, Guyatt G, Cook D, C Kergl, J Mancebo, et al. (2001) Predicting success in weaning from mechanical ventilation. Chest 120: 400S. 
3. Baptistella AR, Sarmento FJ, da Silva KR, Marcelo Taglietti, Radamés Ádamo Zuquello, et al. (2018) Predictive factors of weaning from mechanical ventilation and extubation outcome: A systematic review. J Crit Care 48: 56-62.

4. Jeong ES, Lee K (2018) Clinical application of modified burns wean assessment program scores at first spontaneous breathing trial in weaning patients from mechanical ventilation. Acute Crit Care 4: 260268.

5. Tanios MA, Nevins ML, Hendra KP, Pierre Cardinal, Jill E Allan, et al (2006) A randomized, controlled trial of the role of weaning predictors in clinical decision making. Crit Care Med 34(10): 2530.

6. Keykha A, Dahmardeh AR, Khoshfetrat M (2017) Comparison of Success Rate of Weaning from Mechanical Ventilation Using Burn's Wean Assessment Program and Routine Method. Crit Care Nurs J 10(3): e12557.

7. Jiang JR, Yen SY, Chien JY, Liu HC, Wu YL, et al. (2014) Predicting weaning and extubation outcomes in long-term mechanically ventilated patients using the modified Burns Wean Assessment Program scores. Respirology 19: 576-582.

8. Abdelaleem NA, Mohamed SAA, Abd ElHafeez AS, Bayoumi HA (2020) Value of modified Burns Wean Assessment Program scores in the respiratory intensive care unit: an Egyptian study. Multidisciplinary Respiratory Medicine 15: 691.

9. Yang Y, Peng F, Wang R, Ming Yange, Kai Guan, et al. (2020) The deadly coronaviruses: The 2003 SARS pandemic and the 2020 novel coronavirus epidemic in China. J Autoimmun 109: 102434.

10. Luo M, Meib Z, Wei L, Shumei Cao, Shiheng Su, et al. (2020) Precautions for weaning from invasive mechanical ventilation with critically ill COVID-19. Heart \& Lung 49(6): 869-871.

11. Fujii E, Fujino K, Tanaka Mizuno S, Yutaka Eguchi (2018) Variation of risk factors for cause-specific reintubation: a preliminary study. Can Respir J 3654251.

\section{Your next submission with Juniper Publishers will reach you the below assets}

- Quality Editorial service

- Swift Peer Review

- Reprints availability

- E-prints Service

- Manuscript Podcast for convenient understanding

- Global attainment for your research

- Manuscript accessibility in different formats

( Pdf, E-pub, Full Text, Audio)

- Unceasing customer service

Track the below URL for one-step submission https://juniperpublishers.com/online-submission.php 